\title{
Medical Course and Complications After Lung Transplantation
}

\author{
Guillermo Garrido and Gundeep S. Dhillon
}

\section{Overview}

Lung transplantation for patients with end-stage lung disease is associated with improved survival and quality of life $[1,2]$. The median post-lung transplant survival in the current era is approximately 6 years, as compared to a median survival of 4 years among those transplanted between 1990 and 1998 [3]. However, the survival following lung transplantation remains significantly worse as compared to other solid organ transplants. There are certain unique features of lung transplantation that predispose recipients to a multitude of surgical and medical complications.

\section{Specific Relevant Features of the Lung Allograft}

The lungs normally have a dual blood supply, consisting of 1) large pulmonary arteries that provide desaturated blood under low pressure for alveolar gas exchange and 2) smaller bronchial arteries that provide oxygenated blood under systemic pressure for nutrition and oxygenation of the bronchi and lung tissue. As the only solid organ transplant that does not undergo primary systemic (i.e., bronchial) arterial revascularization at the time of surgery, lung transplants rely on the deoxygenated pulmonary arterial circulation and are especially vulnerable to the effects of injury and ischemia [4].

It has been hypothesized that the absence of the bronchial system in the lung allograft increases susceptibility to microvascular injury and chronic airway ischemia, which may be implicated in the genesis of chronic rejection and other complications [5]. Similarly, the native lymphatics and the neural supply to lung allografts are disrupted at the time of trans-

G. Garrido $(\bowtie) \cdot$ G. S. Dhillon

Division of Pulmonary and Critical Care, Department of Medicine, Stanford University School of Medicine, Stanford, CA, USA

e-mail: gdhillon@stanford.edu plantation. The impact of these disruptions on lung transplant outcomes remains unclear, though it is possible that these changes lead to higher susceptibility to the development of pulmonary edema and infections, worse airway clearance, and ineffective cough [6]. Lastly, the lung allografts have higher exposure to immunogenic compounds, as compared to other organs, by ventilation. The ongoing exposure to various inhaled injurious agents may also predispose lung allografts to develop chronic rejection.

\section{Post-Lung Transplantation Complications}

There is a vast array of complications from lung transplantation. Broadly these complications can be divided into noninfectious and infectious complications and have been summarized in Table 26.1. These complications arise at different times in the postoperative period [7]. The understanding of timing of various complications post-lung transplant can lead to early recognition and management of these complications.

\section{Noninfectious Complications}

\section{Primary Graft Dysfunction (PGD)}

PGD is a syndrome of acute lung injury that ensues within the first 72 hours after lung transplant. It is manifested by the early development of bilateral pulmonary infiltrates, hypoxemia with a reduced $\mathrm{PaO} 2 / \mathrm{FiO} 2$ ratio $(<300)$, without an identifiable cause. The diagnosis of PGD is one of the exclusions. The other causes of graft dysfunction such as infection, hyperacute rejection, cardiogenic pulmonary edema, and pulmonary venous anastomotic obstruction should be excluded [8]. PGD is thought to be due to overexuberant infiltration of monocytes, neutrophils, and T cells in response to transplant-mediated immune signals from endothelium, 
Table 26.1 Noninfectious and infectious complications post-lung transplant

\begin{tabular}{|c|c|}
\hline Noninfectious complications & Infectious complications \\
\hline $\begin{array}{l}\text { Primary graft dysfunction } \\
\text { (PGD) } \\
\text { Venous thromboembolism } \\
\text { (VTE) } \\
\text { Nerve injury } \\
\text { Diaphragmatic dysfunction } \\
\text { (phrenic nerve) } \\
\text { Gastroparesis (vagus } \\
\text { nerve) } \\
\text { Pleural } \\
\text { Effusions } \\
\text { Pneumothorax, } \\
\text { hemothorax, chylothorax } \\
\text { Bronchopleural fistula } \\
\text { Pleural fibrosis } \\
\text { Vascular anastomotic } \\
\text { complications } \\
\text { Airway anastomotic } \\
\text { complications } \\
\text { Rejection } \\
\text { Acute cellular rejection } \\
\text { Antibody-mediated } \\
\text { rejection } \\
\text { Chronic lung allograft } \\
\text { dysfunction } \\
\text { Bronchiolitis obliterans } \\
\text { syndrome (BOS) } \\
\text { Restrictive allograft } \\
\text { syndrome (RAS) } \\
\text { Post-transplant malignancies } \\
\text { Metabolic } \\
\text { Hyperammonemia } \\
\text { Diabetes mellitus } \\
\text { Acute kidney injury, } \\
\text { chronic kidney disease } \\
\text { Osteoporosis } \\
\text { Dyslipidemia } \\
\text { Cardiovascular (arrhythmias, } \\
\text { coronary artery disease) } \\
\text { Miscellaneous issues } \\
\text { (psychiatric, gastrointestinal, } \\
\text { sarcopenia) }\end{array}$ & $\begin{array}{l}\text { Bacterial infections } \\
\text { Pseudomonas aeruginosa } \\
\text { Burkholderia cepacia } \\
\text { Staphylococcus aureus } \\
\text { (including methicillin-resistant), } \\
\text { other gram-negative organisms } \\
\text { Streptococcus pneumoniae } \\
\text { Clostridium difficile } \\
\text { Nocardia } \\
\text { Fungal infections } \\
\text { Aspergillus } \\
\text { Fusarium } \\
\text { Scedosporium } \\
\text { Mucormycosis } \\
\text { Candida, Pneumocystis jiroveci } \\
\text { Cryptococcus } \\
\text { Endemic fungi: Histoplasma } \\
\text { capsulatum, Coccidioides } \\
\text { immitis, Blastomyces } \\
\text { dermatitidis } \\
\text { Viral infections } \\
\text { Cytomegalovirus (CMV) } \\
\text { Herpesviruses } \\
\text { JC virus } \\
\text { BK virus } \\
\text { Respiratory syncytial virus } \\
\text { (RSV), parainfluenza, and other } \\
\text { respiratory viruses }\end{array}$ \\
\hline
\end{tabular}

epithelium, and alveolar macrophages. The interaction between these cells leads to release of cytokines, reactive oxygen intermediates, and proteolytic enzymes leading to graft dysfunction [9]. The severity of PGD falls along a spectrum, ranging from mild dysfunction to severe lung injury. PGD can affect $10-25 \%$ of transplanted patients, and the 30 -day mortality can be as high as $50 \%$. Furthermore, severe PGD after lung transplantation has been associated with development of subsequent chronic rejection and graft dysfunction [10].

The management of PGD is largely supportive and includes lung-protective ventilation strategies (low tidal volume, high positive end-expiratory pressure), judicious fluid management, inhaled nitric oxide or other inhaled pulmonary vasodilators to improve oxygenation, and extracorporeal life support (ECLS) for the most severe cases. Re-transplantation is an option for highly selected cases, but it is generally not recommended due to suboptimal outcomes [11].

\section{Venous Thromboembolism (VTE)}

Lung transplant recipients are at increased risk of VTE. The risk factors include major surgery status, hypercoagulable state, high dose of corticosteroids, immobility, and indwelling vascular access. The reported incidences of pulmonary embolism (PE) and deep venous thrombosis (DVTs) postlung transplantation are approximately $5-15 \%$ and $20-45 \%$, respectively [12]. The pulmonary embolism in setting of limited pulmonary reserve due to PGD, postoperative atelectasis, and single-lung transplantation can have catastrophic consequences, thus underscoring the need for early and appropriate VTE prophylaxis after lung transplantation [13].

The diagnosis can be made with computed tomography (CT) pulmonary angiography, ventilation-perfusion scan, or by documentation of DVT by Doppler ultrasonography. The treatment is the same as for VTEs in general, although the risk of postoperative bleeding needs to be weighed against the risk of PE. The choice of anticoagulant is based on kidney function, periprocedural reversibility of anticoagulant effect, and drug interactions, with unfractionated heparin, low-molecular-weight heparin, and/or warfarin being by far the most common agents used. In case of ongoing bleeding or high risk of bleeding, inferior vena cava filters can be used as a temporizing measure.

\section{Nerve Injury}

Inadvertent injury to various intrathoracic nerves during lung transplantation is a well-recognized and common complication. The most commonly affected structures are the phrenic and vagus nerves.

The reported rates of phrenic nerve injury have ranged from 3\% to 9\% in lung transplant cases. This rate can be as high as $40 \%$ in combined heart-lung transplantation $[14,15]$. Diaphragmatic dysfunction as a consequence of phrenic nerve injury can present clinically with dyspnea, hypoventilation and hypercapnia, and hypoxemia or as difficult wean from the ventilator. Diaphragmatic paralysis can lead to increased length of stay and ventilator dependence. Diagnosis can be confirmed by documenting paradoxical movement of affected diaphragm during quiet and deep breathing, using fluoroscopy or ultrasound visualization.

The vagal nerve injury post-lung transplantation can lead to gastroparesis with associated risk of gastroesophageal reflux (GERD) and aspiration events. These in turn can place lung allograft at risk for recurrent infections, bronchiectasis, 
and possibly chronic allograft dysfunction [16-18]. Common symptoms of gastroparesis include early satiety, decreased appetite, abdominal pain, and bloating. A diagnosis is usually made by a nuclear medicine gastric emptying study. The potential management strategies include minimizing transit delaying medications (e.g., opioids), the use of pro-motility agents, placement of post-pyloric feeding tubes, botulinum toxin injection to the pylorus, and surgical fundoplication in conjunction with pyloroplasty [17].

\section{Pleural Complications}

The pleural complications in early post-lung transplantation period include pleural effusions, hemothorax, pneumothorax, empyema, chylothorax, and interpleural communication. These complications usually arise as a result of the pleural disruption from the surgery itself, though rejection and immunosuppressive regimens may also play a role. The risk factors for the development of pleural complications include previous thoracic surgery, pleural adhesions, and donor-recipient size mismatch $[19,20]$.

Pleural effusions are extremely common in the early postlung transplant period. The reported incidence has been $100 \%$ in some series $[19,20]$. All patients have chest tubes in place immediately post-operation to allow lung re-expansion, pleural air, and fluid drainage. The increased amount of pleural fluid post-lung transplantation is related to capillary leak due to allograft ischemia reperfusion, fluid overload, bleeding, and surgical interruption of allograft lymphatics at the time of explantation [19, 20].

Late pleural effusions can be a consequence of infection, acute rejection, trapped lung physiology from pleural fibrosis, or malignancy $[21,22]$.

In general, all pleural effusions need to be evaluated to rule out complicated effusions such as hemothorax, empyema, and chylothorax. These entities have all been associated with negative patient outcomes and are treated with a range of medical and surgical procedures depending on the condition and severity. For example, a chylothorax might necessitate mechanical interruption of thoracic duct, or hemothorax may need thoracotomy for control of bleeding.

Pneumothoraxes are common after lung transplantation. They can result from donor-recipient size mismatch, bronchopleural fistulas that occur secondary to operative injury or bronchial anastomoses dehiscence, or as a consequence of transbronchial biopsies performed in the course of allograft evaluation. Small and stable pneumothoraxes after lung transplantation can be managed by watchful waiting, though larger or symptomatic pneumothorax may require chest tube drainage. An inadequately drained, hemodynamically significant pneumothorax can be a medical emergency necessitating urgent drainage [23, 24]. In patients who have undergone sequential bilateral lung transplantation (BSLT) or heart-lung transplantation (HLT), interpleural communication due to surgical severance of the pleural recesses that separate the left and right pleural spaces can develop. This entails that pleural issues in these patients must be managed aggressively as pneumothoraxes can be bilateral and life threatening, and empyema can spread quickly.

\section{Vascular Anastomotic Complications}

Vascular anastomotic complications can arise either early or late in the post-transplant course and can have very severe adverse consequences. Pulmonary artery stenosis can be secondary to mechanical kinking, disruption, or narrowing of the anastomosis, sometimes due to the particulars of donor anatomy or due to thrombosis [25]. The clinical picture is usually consistent with pulmonary hypertension and right ventricular failure. Diagnosis can be made through pulmonary angiography and can be managed with interventions such as balloon dilation and stent deployment. Occasionally, patients may require surgery for definitive management of the stenosis.

Pulmonary vein occlusion post-lung transplantation is a rare but serious complication. The commonest cause of pulmonary vein occlusion is the development of thrombosis at the anastomotic junction of the pulmonary veins and the left atrium, though inadvertent narrowing or ligation of pulmonary veins has also been reported. The potential clinical consequences include hypoxic respiratory failure, pulmonary edema, and cardio-embolic events. This entity should be included in the differential diagnosis of a patient with acute pulmonary edema post-lung transplantation. Diagnosis is usually made by transesophageal echocardiography or CT angiography $[26,27]$.

\section{Airway Anastomotic Complications}

The airway complications after lung transplantation can be classified by time of occurrence. Early anastomotic complications, usually within 1 month of transplantation, include infection, dehiscence, and necrosis at the anastomotic sites. Later complications include bronchopleural, bronchovascular and bronchomediastinal fistulae, excessive granulation tissue, bronchomalacia, and airway stenosis. Airway anastomotic complications do not seem to be associated with decreased survival; however, they do negatively impact quality of life and significantly increase healthcare resource utilization [28].

The risk factors for airway anastomotic complications include colonization with Burkholderia cepacia and Aspergillus fumigatus, PGD, acute rejection, prolonged mechanical ventilation, and sirolimus use prior to anastomotic healing [29, 30]. 
Bronchial necrosis and dehiscence occur 1-2 weeks after transplant. They can present with dyspnea, difficulty weaning from the ventilator, persistent air leak on the water seal, pneumomediastinum, and subcutaneous emphysema and infection, with symptoms ranging from mild to severe. Depending on the severity, management can range from observation and antibiotics to minimally invasive or surgical repair.

Bronchial stenosis is the narrowing of the airway lumen, usually at the site of the anastomosis. Patients can present with wheezing, cough, post-obstructive pneumonias, decline in pulmonary function tests (PFTs), and stridor. The bronchial narrowing can also present distal to the anastomosis causing lobar lobe collapse. This syndrome occurs 2-6 months post-transplant but can present as late as 12 months. Treatment options include close monitoring, bronchial dilatation with or without stent placement, and re-transplantation [31].

\section{Rejection}

Allograft rejection is a major cause of morbidity and mortality post-lung transplantation. At least a third of patients are reported to have acute rejection in the first year after transplant. Acute rejection in itself seldom leads to mortality, but it is a main risk factor for the development of chronic rejection. The chronic rejection of lung allograft is the major hurdle to long-term survival after transplantation. Despite the use of potent and novel immunosuppressive regimens, the incidence of chronic rejection and long-term survival post-transplant has remained essentially unchanged over the last two decades [1, 32].

\section{Acute Cellular Rejection}

Acute cellular rejection (ACR) is the most common kind of acute lung transplant rejection and is mediated by $\mathrm{T}$ lymphocytes. Symptoms and signs of ACR include dyspnea, cough, fever, and hypoxia. High-grade rejection may be associated with respiratory failure. Mild ACR can be asymptomatic and frequently detected on surveillance pulmonary function testing and/or transbronchial biopsies. Current imaging modalities are not diagnostic but may reveal useful findings such as infiltrates and ground-glass opacities [32, 33]. Flexible bronchoscopy with transbronchial biopsies is the gold standard for diagnosis. Histologically, ACR is characterized by the presence of perivascular and/or peribronchiolar (grade B) lymphocytes in the absence of infectious etiologies [32, 34, 35]. Risk factors for ACR include the number of HLA mismatches between donor and recipient, although it is unclear which specific HLAs have more impact. Other reported risk factors are age, with older patients having more rejection, immunosuppressive regimen used (tacrolimus regimens reject less), other genetic factors such as IL-10 production, and documented GERD. ACR has also been documented following infections with certain viruses, such as rhinovirus, parainfluenza virus, influenza virus, human metapneumovirus, coronavirus, and respiratory syncytial virus.

The treatment for ACR is not uniform, and high-quality randomized controlled trials are lacking. There is wide agreement that severe cases of ACR must be treated, but there is variability among transplant centers on whether to treat milder cases. The mainstay of therapy is high-dose corticosteroids. In cases that are refractory or recurrent, usually the immunosuppressive regimen gets intensified or altered, and medications such as anti-thymocyte globulin (ATG), antiinterleukin 2-receptor (IL-2R) antagonists, muromonab-CD3 (OKT3), and alemtuzumab (anti-CD52 monoclonal antibody), among others, can be used [36, 37].

\section{Antibody-Mediated Rejection}

Antibody-mediated rejection (AMR) is believed to be mediated by donor-specific antibodies (DSA) against human leukocyte antigens (HLA) and other donor antigens. These antibodies may have been present in the recipient prior to transplant, although most appear to develop after transplantation. AMR is described as the combination of the following: donor-specific anti-HLA antibodies, evidence of complement deposition in allograft biopsies, histologic tissue injury, and clinical allograft dysfunction [38]. Once the aforementioned antibodies bind their receptors in the graft, they are capable of binding complement, specifically C1q. This can trigger complement-mediated cell destruction and inflammation. The development of de novo anti-HLA antibodies is associated with poor prognosis [39, 40].

The mainstay of AMR management involves depletion and/or neutralization of anti-HLA antibodies by plasma exchange or intravenous immunoglobulin (IVIG), followed by rituximab infusion. Rituximab is an anti-CD-20 chimeric antibody that targets B-cell function and can decrease production of antibodies. In cases of refractory AMR, newer agents such as bortezomib (anti-proteasome 26s) and the anticomplement antibody eculizumab have been tried with limited success. Successful clearance of anti-HLA antibodies has been associated with decreased risk of development of chronic rejection following AMR [32].

\section{Chronic Lung Allograft Dysfunction}

The term chronic lung allograft dysfunction (CLAD) encompasses pathologies that lead to chronic dysfunction of lung allograft. CLAD is predominantly a consequence of chronic rejection and is a major hurdle to long-term survival. The two major phenotypes of CLAD include (i) bronchiolitis obliterans syndrome (BOS) and (ii) restrictive allograft syndrome (RAS) [41, 42].

BOS is the predominant form of CLAD and is the number one cause of death after 1 year of transplantation. It is 
reported to occur in up to $76 \%$ of lung transplant recipients at 10 years post-transplant, and it is a major cause of morbidity, negative impact in quality of life, and increased costs. BOS is defined by a sustained ( $>3$ weeks) decline in the forced expiratory volume in the first second of expiration (FEV1); provided alternative causes of pulmonary dysfunction have been excluded. At the tissue level, the hallmark of BOS is obliterative bronchiolitis (OB), which is an inflammatory/fibrotic process affecting the small non-cartilaginous airways (membranous and respiratory bronchioles) characterized by subepithelial fibrosis causing partial or complete luminal occlusion [43, 44].

Risk factors include prior episodes of acute rejection, cytomegalovirus infection (CMV), community-acquired respiratory viruses (CARV) infection, history of PGD, isolation of Aspergillus fumigatus and Pseudomonas aeruginosa, the presence of GERD, and other immune-mediated factors [44]. The diagnosis can be made conditionally without histopathology (BOS) or definitively with histopathology (BO). Transbronchial biopsy is an insensitive method for detecting $\mathrm{BO}$, and the clinical use of BOS is the favored method for diagnosis and monitoring.

The treatment of BOS is disappointing in terms of outcomes; often success is measured in slowing the decline or stabilizing it. Beyond augmentation of immunosuppression, azithromycin, extracorporeal photopheresis, montelukast, methotrexate, aerosolized cyclosporine, alemtuzumab, and total lymphoid irradiation have been used with limited success $[44,45]$.

RAS has been more recently described and occurs in less than a third of patients with CLAD. These patients present with predominant restriction, and the survival is worse as compared to patients with BOS. The median survival postdiagnosis is 8 months. CT scan shows interstitial opacities, ground-glass opacities, upper lobe-dominant fibrosis, and honeycombing. The only identified risk factor for the development of RAS is late-onset diffuse alveolar damage (DAD), occurring later than 3 months after lung transplant. There is no proven treatment for this condition, and re-transplantation remains technically challenging $[46,47]$.

\section{Post-transplant Malignancies}

Lung transplant and associated immunosuppression are an established risk factor for development of cancer [48]. The commonest malignancy post-lung transplant is the squamous cell cancer of the skin. The single-lung transplant recipients are at higher risk of development of lung cancer in their native lungs. This increased risk is in part related to the increased risk of cancer due to underlying disease (e.g., emphysema, idiopathic pulmonary fibrosis) [49, 50]. Similarly, the transplant recipients with cystic fibrosis remain at an elevated risk for development of gastrointestinal malignancies [49]. It is imperative that transplant recipients adhere to age-appropriate health screening after transplant. Additionally, all lung transplant recipients should undergo skin cancer screening annually.

The risk is especially high for of viral infection associated malignancies such as lymphoma, Kaposi sarcoma, and anogenital cancers [49]. Post-transplant lymphoproliferative disorders (PTLD) encompass an array of diseases involving clonal expansion of B lymphocytes, ranging from polyclonal benign disorders to aggressive malignant lymphomas. The reported incidence of non-Hodgkin lymphoma post-lung transplant has been as high as 28 cases/100,000 person-years [49]. There is a significant association between PTLD and Epstein-Barr virus (EBV) infection, especially in patients who acquire infection the novo after being transplanted. PTLD is managed by reducing the intensity of immunosuppression if possible, with specific chemotherapy for more severe and refractory cases.

\section{Metabolic Complications}

\section{Hyperammonemia}

Hyperammonemia affects $1-4 \%$ of the lung transplant population; it is a rare but potentially fatal complication. It can be secondary to systemic infection with Mycoplasma hominis and Ureaplasma, which break down urea as an energy source, generating ammonia as a waste product. This likely represents a donor-derived infection and can respond to early appropriate antibiotic treatment [51]. Postoperative liver dysfunction and urea-cycle enzyme deficiencies can also cause hyperammonemia.

\section{Diabetes Mellitus}

Diabetes mellitus (DM) is common in lung transplant recipients, with $25-30 \%$ of patients developing it in the first year post-transplant and up to $40 \%$ at 5 years. The use of glucocorticoids, calcineurin inhibitors, obesity, and advanced age is a significant risk factor for the development of DM. The development of DM in lung transplant recipients is associated with decreased survival. A close and judicious glycemic control is indicated in this patient population $[52,53]$.

\section{Acute Kidney Injury and Chronic Kidney Disease}

Patients who undergo lung transplantation have multiple risk factors to develop acute kidney injury (AKI) post-transplant, including decreased renal perfusion before, during, and/or after surgery, drug toxicities, and systemic infections. AKI affects as many as $70 \%$ of patients with approximately $8 \%$ patients requiring renal replacement therapy (RRT). The postoperative renal failure necessitating the use of RRT is associated with increased risk of early mortality [54, 55]. 
By 3 years, 25\% of surviving lung transplant recipients develop severe renal dysfunction (serum creatinine $>2.5 \mathrm{mg}$ / $\mathrm{dl}$ ), and that percentage rises to $40 \%$ at 10 -year mark [1]. The risk factors for development of chronic kidney disease (CKD) include older age, DM, hypertension, smoking history, and use of nephrotoxic drugs. CKD is also associated with higher mortality in lung transplant recipients [56].

\section{Other Metabolic Complications}

Recipients of lung transplant are at risk for development of osteopenia and osteoporosis due to multiple factors such as malnutrition, immobility, chronic corticosteroid use, calcineurin inhibitor use (e.g., tacrolimus), and other comorbidities. The strategies to prevent and reverse bone losses after transplant need to be proactively implemented. Treatment includes adequate supplementation of calcium, vitamin D, use of bisphosphonates, enhancing physical activity, and minimizing contributing medications, if possible [57, 58].

Dyslipidemia is also very common in lung transplant recipients, as high as 59\%, and it may be related to the aforementioned metabolic risk factors. Treatment usually entails lifestyle modifications and cholesterol lowering medications.

\section{Cardiovascular Complications}

There are multiple cardiac complications after lung transplantation, both short and long term. Atrial dysrhythmias are very frequent in the early postoperative period, likely related to stress of major surgery, catecholamine surge, medication side effects, and mechanical stresses related to vascular anastomoses. The reported incidence has been as high as $25-35 \%$ [59, 60]. These arrhythmias are usually managed with medications aimed at rate and rhythm control. Hemodynamically significant and/or refractory arrhythmias may require electric cardioversion. Atrial dysrhythmias are associated with increased length of hospital stay and increased mortality $[59,60]$.

Over the long term, lung transplant recipients are at increased risk for developing coronary artery disease (CAD). As they progress into long-term survival, these patients have cumulative impact from risk factors previously discussed in this chapter, namely, DM, dyslipidemia, CKD, hypertension, chronic corticosteroid use, and other immunosuppressive medication. These risk factors should be carefully managed to decrease the impact of CAD and related complications, with a combination of lifestyle modifications and specific medical therapies [61].

\section{Miscellaneous Issues}

Lung transplant recipients experience a decrease in skeletal muscle strength and function, including respiratory and limb muscles. This is likely related to reduced activity postoperatively and deconditioning, corticosteroid-induced myopathy, critical illness-related weakness (neuropathy/myopathy), and in the case of the diaphragm, phrenic nerve injury. This issue seems to be consistent in lung transplant recipients and independent of pre-transplant diagnosis and surgery type. Muscle weakness, deconditioning, and sarcopenia are associated with adverse outcomes and decrease in quality of life. Aggressive rehabilitation is standard and important in the post-transplant care $[62,63]$.

\section{Infectious Complications}

Lung transplant recipients are at an increased risk for acquiring infections due to the immunosuppressed state, constant environmental pathogen exposure, decreased cough reflex, impaired mucociliary clearance, and lymphatic disruption. Infectious complications are responsible for about a quarter of post-transplant deaths [64].

\section{Bacterial Infections}

Pneumonias are the most significant bacterial infection in lung transplant recipients, and the highest risk is in the first 30 days post-transplant. In the early period, they are more likely to be caused by hospital-acquired organisms, which tend to be more virulent and more resistant to antibiotics. The patients with cystic fibrosis are frequently colonized by multidrug-resistant organisms and are at increased risk of pneumonia post-transplant. In later stages, community-acquired organisms become more prevalent. Moreover, throughout the post-transplant period, the patients are susceptible to numerous opportunistic infections [65].

Other commonly encountered bacterial infections in this patient population include pleural space infections, blood stream infections (BSIs), and soft tissue infections. The BSIs and empyema carry a high risk of morbidity and mortality [66, 67].

Pseudomonas aeruginosa, Burkholderia cepacia, Staphylococcus aureus (including methicillin-resistant), and other gram-negative organisms are common causes of serious infections in post-lung transplant period. These organisms have high rates of antibiotic resistance and are associated with worse outcomes [68-70]. Streptococcus pneumoniae is the most common cause of communityacquired pneumonia, and immunosuppressed patients have increased risk of disseminated infection [71]. Clostridium difficile associated diarrhea is a major complication in hospitalized, immunosuppressed and debilitated patients and is associated with increased hospital length of stay and mortality [72]. 


\section{Fungal Infections}

Molds are common fungal entities affecting lung allografts. Aspergillus spp. are the most common and have a predilection for the respiratory tract [73]. Lung transplants have the highest incidence of invasive aspergillosis among solid organ transplant recipients, and it is the most common invasive fungal infection in lung transplant. Aspergillus is ubiquitous in the environment and is acquired by inhalation. There are three main described presentations: invasive pulmonary disease, tracheobronchial aspergillosis, and disseminated disease, all of which are associated with varying degrees of increased mortality. Other implicated molds include Fusarium, Scedosporium, and Mucormycosis. These infections are difficult to treat and are associated with poor clinical outcomes [73]. Candida spp. are another common pathogen in lung transplant setting. Oral candidiasis is the most common manifestation of this infection. However, candida infections can also manifest as candidemia, empyema, surgical wound infection, and disseminated disease. Serious candida infections have been associated with increased mortality, though rates have been declining over time [74]. Other fungal infections in this patient population include opportunistic infections, such as Pneumocystis jiroveci and Cryptococcus, as well as endemic fungi, such as Histoplasma capsulatum, Coccidioides immitis, and Blastomyces dermatitidis $[75,76]$.

\section{Viral Infections}

Viral infections contribute to morbidity and mortality from acute infection and have been associated with an increased risk of rejection, chronic allograft dysfunction, lymphoproliferative and other neoplastic diseases, and other extra pulmonary organ damage [77].

Cytomegalovirus (CMV) is the most significant viral infection occurring in solid organ transplant recipients and is the second most common infection, after bacterial pneumonia. CMV infection can range from latent infection, to asymptomatic viremia, to CMV disease manifested with clinical symptoms and end-organ involvement. Severity of disease may range from mild to life threatening. When there is organ damage, affected organs can include the lungs, pancreas, intestines, retina, kidney, liver, and brain. CMV disease is associated with increased mortality [77, 78]. Other notable DNA viruses from the Herpesviridae family include Epstein-Barr virus (EBV), which is associated with increased risk of PTLD and other malignancies, herpes simplex virus (HSV) 1 and 2, varicella-zoster virus (VZV), and human Herpesvirus 6, 7, and 8 [77].

Community-acquired respiratory viruses, including influenza, are a major source of respiratory symptoms and mor- bidity after lung transplantation. These infections may also be associated with development of chronic allograft dysfunction [79].

\section{Survival, Overall Prognosis, and Follow-Up Care}

Currently, the median survival for all adult lung transplant recipients is 6 years [1]. Bilateral lung recipients appear to have a better median survival compared to single-lung recipients ( 7 versus 4.5 years) [1]. Overall lung transplantation confers clinically meaningful and statistically significant improvements in health-related quality of life (HRQOL). Greater than $80 \%$ of lung transplant recipients report no activity limitations [80].

The care of lung transplant recipients is multidisciplinary, labor intensive, and comprehensive. It includes management of immunosuppression regimen, opportunistic infection prophylaxis, prevention and management of various comorbidities, and complications. A typical medication regimen consists of three classes of immunosuppression drugs (i.e., calcineurin inhibitor, cell-cycle inhibitor, and corticosteroids), as well as opportunistic infection prophylaxis against Pneumocystis jiroveci, other fungal infections, and CMV.

In early postoperative period and after hospital discharge, the recipients are closely monitored in outpatient setting. Typical clinic visits include thorough medication reconciliation, clinical exam, pulmonary function testing, chest radiographs, and laboratory examinations. The role of surveillance bronchoscopies with transbronchial biopsies in monitoring of lung allograft remains unclear.

\section{Conclusions}

While lung transplantation improves survival and quality of life in patients with end-stage lung disease, it is associated with multitude of noninfectious and infectious complications. Lung transplant recipients have one of the shortest survival rates among other solid organ recipients, due to some unique characteristics of the lung allograft, including its unique blood supply and risk for ischemia, disruption of the native lymphatics and the neural supply during the transplant surgery, and exposure to immunogenic entities via ventilation. Among noninfectious complications, PGD, VTE, and rejection are the most important ones. CLAD affects most patients long term and remains a significant clinical concern and contributor to early mortality in lung transplant recipients. Lung transplant recipients are also at increased risk for a variety of malignancies, due to their underlying disease, comorbidities, and immunosuppressed status; thus they require vigilant monitoring and screening for cancer. Infectious complications (i.e., bacterial, fungal, viral) are also 
important contributors to morbidity and mortality, with bacterial pneumonias and CMV most commonly seen. Patients require multidisciplinary and intensive follow-up and aftercare, ongoing vigilance, early recognition and treatment, and open and frequent communication between recipients, caregivers, and healthcare team providers.

\section{References}

1. Yusen RD, Christie JD, Edwards LB, Kucheryavaya AY, Benden C, Dipchand AI, et al. The registry of the International Society for Heart and Lung Transplantation: thirtieth adult lung and heart-lung transplant report--2013; focus theme: age. J Heart Lung Transplant. 2013;32(10):965-78.

2. Gross CR, Savik K, Bolman RM 3rd, Hertz MI. Long-term health status and quality of life outcomes of lung transplant recipients. Chest. 1995;108(6):1587-93.

3. Lund LH, Khush KK, Cherikh WS, Goldfarb S, Kucheryavaya AY, Levvey BJ, et al. The registry of the International Society for Heart and Lung Transplantation: thirty-fourth adult heart transplantation Report-2017; focus theme: allograft ischemic time. J Heart Lung Transplant. 2017;36(10):1037-46.

4. Contreras AG, Briscoe DM. Every allograft needs a silver lining. J Clin Invest. 2007;117(12):3645-8.

5. Dhillon GS, Zamora MR, Roos JE, Sheahan D, Sista RR, Van der Starre P, et al. Lung transplant airway hypoxia: a diathesis to fibrosis? Am J Respir Crit Care Med. 2010;182(2):230-6.

6. Nicolls MR, Dhillon GS, Daddi N. A critical role for airway microvessels in lung transplantation. Am J Respir Crit Care Med. 2016;193(5):479-81.

7. Ahmad S, Shlobin OA, Nathan SD. Pulmonary complications of lung transplantation. Chest. 2011;139(2):402-11.

8. Snell GI, Yusen RD, Weill D, Strueber M, Garrity E, Reed A, et al. Report of the ISHLT working group on primary lung graft dysfunction, part I: definition and grading-a 2016 consensus group statement of the International Society for Heart and Lung Transplantation. J Heart Lung Transplant. 2017;36(10):1097-103.

9. Gelman AE, Fisher AJ, Huang HJ, Baz MA, Shaver CM, Egan TM, et al. Report of the ISHLT working group on primary lung graft dysfunction part III: mechanisms: a 2016 consensus group statement of the International Society for Heart and Lung Transplantation. J Heart Lung Transplant. 2017;36(10):1114-20.

10. Diamond JM, Arcasoy S, Kennedy CC, Eberlein M, Singer JP, Patterson GM, et al. Report of the International Society for Heart and Lung Transplantation working group on primary lung graft dysfunction, part II: epidemiology, risk factors, and outcomesa 2016 consensus group statement of the International Society for Heart and Lung Transplantation. J Heart Lung Transplant. 2017;36(10):1104-13.

11. Van Raemdonck D, Hartwig MG, Hertz MI, Davis RD, Cypel M, Hayes D Jr, et al. Report of the ISHLT working group on primary lung graft dysfunction part IV: prevention and treatment: a 2016 consensus group statement of the International Society for Heart and Lung Transplantation. J Heart Lung Transplant. 2017;36(10):1121-36.

12. Evans CF, Iacono AT, Sanchez PG, Goloubeva O, Kim J, Timofte I, et al. Venous thromboembolic complications of lung transplantation: a contemporary single-institution review. Ann Thorac Surg. 2015;100(6):2033-9; discussion 9-40.

13. Noda S, Sundt TM 3rd, Lynch JP, Trulock EP, Sundaresan S, Patterson GA. Pulmonary embolectomy after single-lung transplantation. Ann Thorac Surg. 1997;64(5):1459-61.
14. Maziak DE, Maurer JR, Kesten S. Diaphragmatic paralysis: a complication of lung transplantation. Ann Thorac Surg. 1996;61(1):170-3.

15. Ferdinande P, Bruyninckx F, Van Raemdonck D, Daenen W, Verleden G. Leuven lung transplant G. Phrenic nerve dysfunction after heart-lung and lung transplantation. J Heart Lung Transplant. 2004;23(1):105-9.

16. Shafi MA, Pasricha PJ. Post-surgical and obstructive gastroparesis. Curr Gastroenterol Rep. 2007;9(4):280-5.

17. Hooft N, Smith M, Huang J, Bremner R, Walia R. Gastroparesis is common after lung transplantation and may be ameliorated by botulinum toxin-a injection of the pylorus. J Heart Lung Transplant. 2014;33(12):1314-6.

18. Au J, Hawkins T, Venables C, Morritt G, Scott CD, Gascoigne AD, et al. Upper gastrointestinal dysmotility in heart-lung transplant recipients. Ann Thorac Surg. 1993;55(1):94-7.

19. Ferrer J, Roldan J, Roman A, Bravo C, Monforte V, Pallissa E, et al. Acute and chronic pleural complications in lung transplantation. $\mathrm{J}$ Heart Lung Transplant. 2003;22(11):1217-25.

20. Arndt A, Boffa DJ. Pleural space complications associated with lung transplantation. Thorac Surg Clin. 2015;25(1):87-95.

21. Judson MA, Handy JR, Sahn SA. Pleural effusion from acute lung rejection. Chest. 1997;111(4):1128-30.

22. Chhajed PN, Bubendorf L, Hirsch H, Boehler A, Weder W, Tamm M. Mesothelioma after lung transplantation. Thorax. 2006;61(10):916-7.

23. Paranjpe DV, Wittich GR, Hamid LW, Bergin CJ. Frequency and management of pneumothoraces in heart-lung transplant recipients. Radiology. 1994;190(1):255-6.

24. Engeler CE, Olson PN, Engeler CM, Carpenter BL, Crowe JE, Day DL, et al. Shifting pneumothorax after heart-lung transplantation. Radiology. 1992;185(3):715-7.

25. Anaya-Ayala JE, Loebe M, Davies MG. Endovascular management of early lung transplant-related anastomotic pulmonary artery stenosis. J Vasc Interv Radiol. 2015;26(6):878-82.

26. Schulman LL, Anandarangam T, Leibowitz DW, Ditullio MR, McGregor CC, Galantowicz ME, et al. Four-year prospective study of pulmonary venous thrombosis after lung transplantation. J Am Soc Echocardiogr. 2001;14(8):806-12.

27. Gonzalez-Fernandez C, Gonzalez-Castro A, Rodriguez-Borregan JC, Lopez-Sanchez M, Suberviola B, Francisco Nistal J, et al. Pulmonary venous obstruction after lung transplantation. Diagnostic advantages of transesophageal echocardiography. Clin Transpl. 2009;23(6):975-80.

28. Meyers BF, de la Morena M, Sweet SC, Trulock EP, Guthrie TJ, Mendeloff EN, et al. Primary graft dysfunction and other selected complications of lung transplantation: a single-center experience of 983 patients. J Thorac Cardiovasc Surg. 2005;129(6):1421-9.

29. Santacruz JF, Mehta AC. Airway complications and management after lung transplantation: ischemia, dehiscence, and stenosis. Proc Am Thorac Soc. 2009;6(1):79-93.

30. Herrera JM, McNeil KD, Higgins RS, Coulden RA, Flower $\mathrm{CD}$, Nashef SA, et al. Airway complications after lung transplantation: treatment and long-term outcome. Ann Thorac Surg. 2001;71(3):989-93; discussion 93-4.

31. Hasegawa T, Iacono AT, Orons PD, Yousem SA. Segmental nonanastomotic bronchial stenosis after lung transplantation. Ann Thorac Surg. 2000;69(4):1020-4.

32. McManigle W, Pavlisko EN, Martinu T. Acute cellular and antibody-mediated allograft rejection. Semin Respir Crit Care Med. 2013;34(3):320-35.

33. De Vito DA, Hoffman LA, Iacono AT, Zullo TG, McCurry KR, Dauber JH. Are symptom reports useful for differentiating between acute rejection and pulmonary infection after lung transplantation? Heart Lung. 2004;33(6):372-80. 
34. Trulock EP, Ettinger NA, Brunt EM, Pasque MK, Kaiser LR, Cooper JD. The role of transbronchial lung biopsy in the treatment of lung transplant recipients. An analysis of 200 consecutive procedures. Chest. 1992;102(4):1049-54.

35. Stewart S, Fishbein MC, Snell GI, Berry GJ, Boehler A, Burke MM, et al. Revision of the 1996 working formulation for the standardization of nomenclature in the diagnosis of lung rejection. J Heart Lung Transplant. 2007;26(12):1229-42.

36. Martinu T, Pavlisko EN, Chen DF, Palmer SM. Acute allograft rejection: cellular and humoral processes. Clin Chest Med. 2011;32(2):295-310.

37. Levine SM. Transplant/immunology network of the American College of Chest P. A survey of clinical practice of lung transplantation in North America. Chest. 2004;125(4):1224-38.

38. Levine DJ, Glanville AR, Aboyoun C, Belperio J, Benden C, Berry GJ, et al. Antibody-mediated rejection of the lung: a consensus report of the International Society for Heart and Lung Transplantation. J Heart Lung Transplant. 2016;35(4):397-406.

39. Witt CA, Gaut JP, Yusen RD, Byers DE, Iuppa JA, Bennett Bain K, et al. Acute antibody-mediated rejection after lung transplantation. J Heart Lung Transplant. 2013;32(10):1034-40.

40. Morrell MR, Patterson GA, Trulock EP, Hachem RR. Acute antibody-mediated rejection after lung transplantation. J Heart Lung Transplant. 2009;28(1):96-100.

41. Verleden SE, Vos R, Vanaudenaerde BM, Verleden GM. Chronic lung allograft dysfunction phenotypes and treatment. J Thorac Dis. 2017;9(8):2650-9.

42. Gauthier JM, Hachem RR, Kreisel D. Update on chronic lung allograft dysfunction. Curr Transplant Rep. 2016;3(3):185-91.

43. Weigt SS, DerHovanessian A, Wallace WD, Lynch JP 3rd, Belperio JA. Bronchiolitis obliterans syndrome: the Achilles' heel of lung transplantation. Semin Respir Crit Care Med. 2013;34(3):336-51.

44. Meyer KC, Raghu G, Verleden GM, Corris PA, Aurora P, Wilson $\mathrm{KC}$, et al. An international ISHLT/ATS/ERS clinical practice guideline: diagnosis and management of bronchiolitis obliterans syndrome. Eur Respir J. 2014;44(6):1479-503.

45. Benden C, Haughton M, Leonard S, Huber LC. Therapy options for chronic lung allograft dysfunction-bronchiolitis obliterans syndrome following first-line immunosuppressive strategies: a systematic review. J Heart Lung Transplant. 2017;36(9):921-33.

46. Verleden SE, Vandermeulen E, Ruttens D, Vos R, Vaneylen A, Dupont LJ, et al. Neutrophilic reversible allograft dysfunction (NRAD) and restrictive allograft syndrome (RAS). Semin Respir Crit Care Med. 2013;34(3):352-60.

47. Sato M, Waddell TK, Wagnetz U, Roberts HC, Hwang DM, Haroon A, et al. Restrictive allograft syndrome (RAS): a novel form of chronic lung allograft dysfunction. J Heart Lung Transplant. 2011;30(7):735-42.

48. Collett D, Mumford L, Banner NR, Neuberger J, Watson C. Comparison of the incidence of malignancy in recipients of different types of organ: a UK registry audit. Am J Transplant. 2010;10(8):1889-96.

49. Engels EA, Pfeiffer RM, Fraumeni JF Jr, Kasiske BL, Israni AK, Snyder JJ, et al. Spectrum of cancer risk among US solid organ transplant recipients. JAMA. 2011;306(17):1891-901.

50. Arcasoy SM, Hersh C, Christie JD, Zisman D, Pochettino A, Rosengard BR, et al. Bronchogenic carcinoma complicating lung transplantation. J Heart Lung Transplant. 2001;20(10):1044-53.

51. Bharat A, Cunningham SA, Scott Budinger GR, Kreisel D, DeWet CJ, Gelman AE, et al. Disseminated ureaplasma infection as a cause of fatal hyperammonemia in humans. Sci Transl Med. 2015;7(284):284re3.

52. Ye X, Kuo HT, Sampaio MS, Jiang Y, Bunnapradist S. Risk factors for development of new-onset diabetes mellitus after transplant in adult lung transplant recipients. Clin Transpl. 2011;25(6):885-91.
53. Hackman KL, Snell GI, Bach LA. Prevalence and predictors of diabetes after lung transplantation: a prospective, longitudinal study. Diabetes Care. 2014;37(11):2919-25.

54. Wehbe E, Brock R, Budev M, Xu M, Demirjian S, Schreiber MJ Jr, et al. Short-term and long-term outcomes of acute kidney injury after lung transplantation. J Heart Lung Transplant. 2012;31(3):244-51.

55. Fidalgo P, Ahmed M, Meyer SR, Lien D, Weinkauf J, Cardoso FS, et al. Incidence and outcomes of acute kidney injury following orthotopic lung transplantation: a population-based cohort study. Nephrol Dial Transplant. 2014;29(9):1702-9.

56. Paradela de la Morena M, De La Torre BM, Prado RF, Roel MD, Salcedo JA, Costa EF, et al. Chronic kidney disease after lung transplantation: incidence, risk factors, and treatment. Transplant Proc. 2010;42(8):3217-9.

57. Yu TM, Lin CL, Chang SN, Sung FC, Huang ST, Kao $\mathrm{CH}$. Osteoporosis and fractures after solid organ transplantation: a nationwide population-based cohort study. Mayo Clin Proc. 2014;89(7):888-95.

58. Shane E, Papadopoulos A, Staron RB, Addesso V, Donovan D, $\mathrm{McGregor} \mathrm{C}$, et al. Bone loss and fracture after lung transplantation. Transplantation. 1999;68(2):220-7.

59. Raghavan D, Gao A, Ahn C, Torres F, Mohanka M, Bollineni S, et al. Contemporary analysis of incidence of post-operative atrial fibrillation, its predictors, and association with clinical outcomes in lung transplantation. J Heart Lung Transplant. 2015;34(4):563-70.

60. Orrego CM, Cordero-Reyes AM, Estep JD, Seethamraju H, Scheinin S, Loebe M, et al. Atrial arrhythmias after lung transplant: underlying mechanisms, risk factors, and prognosis. J Heart Lung Transplant. 2014;33(7):734-40.

61. Silverborn M, Jeppsson A, Martensson G, Nilsson F. New-onset cardiovascular risk factors in lung transplant recipients. J Heart Lung Transplant. 2005;24(10):1536-43.

62. Maury G, Langer D, Verleden G, Dupont L, Gosselink R, Decramer $\mathrm{M}$, et al. Skeletal muscle force and functional exercise tolerance before and after lung transplantation: a cohort study. Am J Transplant. 2008;8(6):1275-81.

63. Lands LC, Smountas AA, Mesiano G, Brosseau L, Shennib H, Charbonneau M, et al. Maximal exercise capacity and peripheral skeletal muscle function following lung transplantation. J Heart Lung Transplant. 1999;18(2):113-20.

64. Aguilar-Guisado M, Givalda J, Ussetti P, Ramos A, Morales $\mathrm{P}$, Blanes $\mathrm{M}$, et al. Pneumonia after lung transplantation in the RESITRA cohort: a multicenter prospective study. Am J Transplant. 2007;7(8):1989-96.

65. Clark NM, Reid GE, Practice ASTIDCo. Nocardia infections in solid organ transplantation. Am J Transplant. 2013;13(Suppl 4):83-92.

66. Palmer SM, Alexander BD, Sanders LL, Edwards LJ, Reller LB, Davis RD, et al. Significance of blood stream infection after lung transplantation: analysis in 176 consecutive patients. Transplantation. 2000;69(11):2360-6.

67. Nunley DR, Grgurich WF, Keenan RJ, Dauber JH. Empyema complicating successful lung transplantation. Chest. 1999;115(5):1312-5.

68. van Duin D, van Delden C, Practice ASTIDCo. Multidrug-resistant gram-negative bacteria infections in solid organ transplantation. Am J Transplant. 2013;13(Suppl 4):31-41.

69. Dobbin C, Maley M, Harkness J, Benn R, Malouf M, Glanville A, et al. The impact of pan-resistant bacterial pathogens on survival after lung transplantation in cystic fibrosis: results from a single large referral Centre. J Hosp Infect. 2004;56(4):277-82.

70. Garzoni C, Vergidis P, Practice ASTIDCo. Methicillinresistant, vancomycin-intermediate and vancomycin-resistant Staphylococcus aureus infections in solid organ transplantation. Am J Transplant. 2013;13(Suppl 4):50-8. 
71. de Bruyn G, Whelan TP, Mulligan MS, Raghu G, Limaye AP. Invasive pneumococcal infections in adult lung transplant recipients. Am J Transplant. 2004;4(8):1366-71.

72. Dubberke ER, Riddle DJ, Practice ASTIDCo. Clostridium difficile in solid organ transplant recipients. Am J Transplant. 2009;9(Suppl 4):S35-40.

73. Bhaskaran A, Hosseini-Moghaddam SM, Rotstein C, Husain S. Mold infections in lung transplant recipients. Semin Respir Crit Care Med. 2013;34(3):371-9.

74. Silveira FP, Husain S. Fungal infections in lung transplant recipients. Curr Opin Pulm Med. 2008;14(3):211-8.

75. Miller R, Assi M, Practice ASTIDCo. Endemic fungal infections in solid organ transplantation. Am J Transplant. 2013;13(Suppl 4):250-61.
76. Husain S, Wagener MM, Singh N. Cryptococcus neoformans infection in organ transplant recipients: variables influencing clinical characteristics and outcome. Emerg Infect Dis. 2001;7(3):375-81.

77. Clark NM, Lynch JP 3rd, Sayah D, Belperio JA, Fishbein MC, Weigt SS. DNA viral infections complicating lung transplantation. Semin Respir Crit Care Med. 2013;34(3):380-404.

78. Zamora MR. Cytomegalovirus and lung transplantation. Am J Transplant. 2004;4(8):1219-26.

79. Gottlieb J, Schulz TF, Welte T, Fuehner T, Dierich M, Simon AR, et al. Community-acquired respiratory viral infections in lung transplant recipients: a single season cohort study. Transplantation. 2009;87(10):1530-7.

80. Singer JP, Singer LG. Quality of life in lung transplantation. Semin Respir Crit Care Med. 2013;34(3):421-30. 